\title{
A CASE OF INCONTINENTIA PIGMENTI IN A NEW BORN
}

N Ekneligoda ${ }^{1}$, TMR Perera ${ }^{2}$, R Prashana ${ }^{3}$

Key words: Incontinentia Pigmenti, new born, skin manifestations

\section{INTRODUCTION:}

Incontinentia pigmenti (IP) is a rare neuroectodermal dysplasia with an estimated incidence of 0.7 cases per 100,000 births $^{1}$. Up to date approximately 1,200 cases have been reported in scientific literature ${ }^{2}$. IP has a multisystemic involvement where the skin manifestations are the hall mark and could be seen even at birth.

We present a baby girl with typical skin manifestations of IP seen at birth.

\section{CASE REPORT:}

A baby girl was born to healthy nonconsanguineous parents at term via assisted vaginal delivery.Erythematous linear streaks and plaques of vesicular eruptions with hyperpigmentation arranged in a linear configuration, were mainly seen on the limbs and the trunk (Figure $1 \& 2$ ). Lesions were more pronounce on the flexor aspect of the lower limbs (Figure2)

There was a history of premature rupture of membranes for 16 hours without other risk factors for sepsis. Baby was born with a birth weight of $3.08 \mathrm{~kg}$ (median to-1SD) with normal Apgar scores. Her length and occipitofrontal circumference were $50 \mathrm{~cm} \mathrm{~s}$ (median) and $33 \mathrm{~cm} \mathrm{~s}(-1 \mathrm{SD})$ respectively. There was no scaring alopecia, nail dystrophy or skeletal abnormalities. Neurological examination including tone, reflexes, fontanellae and primitive

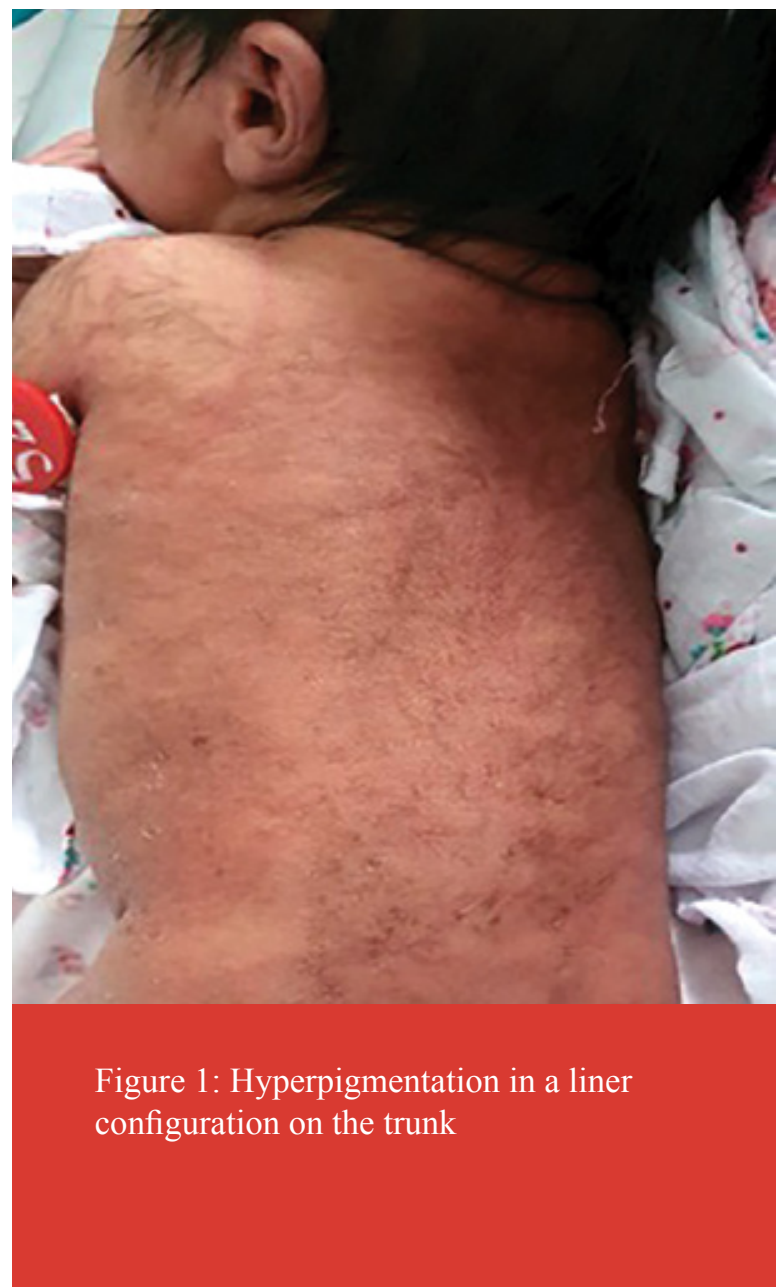

reflexes were normal. Formal eye examination revealed abnormal palpebral and conjunctival dilated vessels with occasional pigmentation.No retinal vasculature abnormality, arteriovenous malformations or lens opacity were noted. A grade-2 ejection systolic murmur was found. Rest of the system examination was unremarkable.

She was the second born with a healthy developmentally normal female sibling. There weren't any miscarriages or similar conditions, bulbous dermatosis, severe allergic reactions and neurological disorders in the family. Mother's venereal disease screening was negative and she 


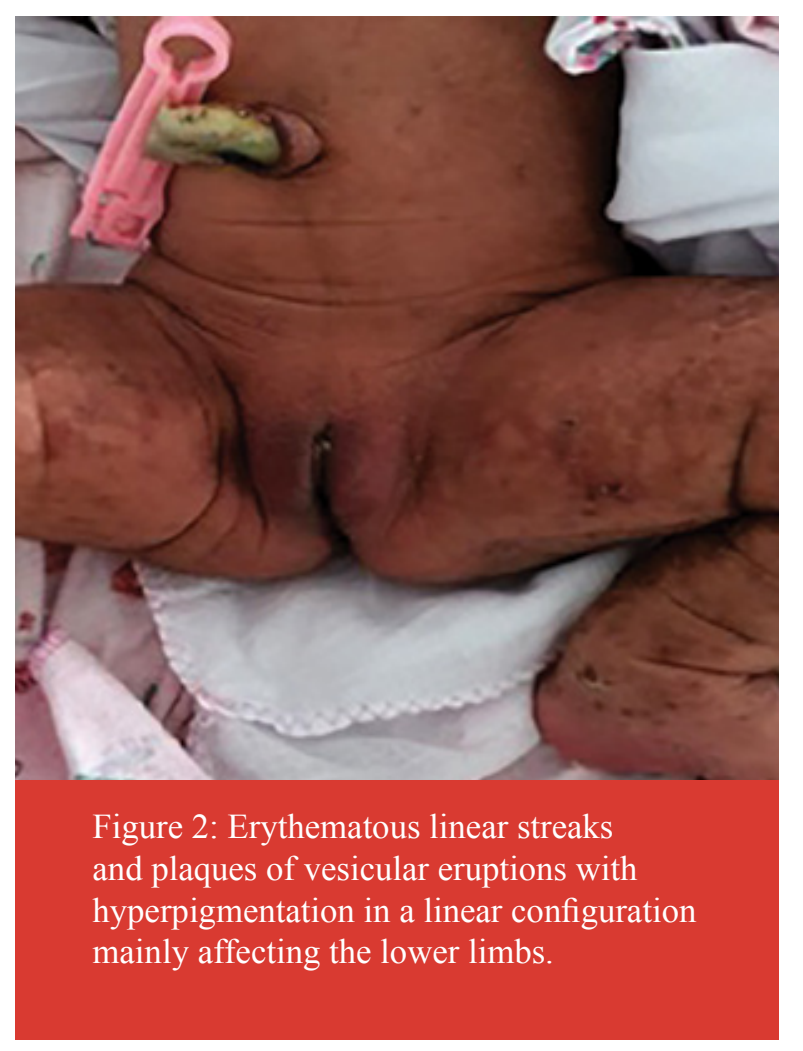

did not have any lesions suggestive of herpes simplex infection. A diagnosis of IP was made on clinical grounds with the presence of typical neonatal rash with ocular manifestations. Skin biopsy was not performed. Mother did not show any features of IP.

Skin lesions were managed with topical antibiotic preparations and aqueous cream. Baby was discharged on day 3 of life after counseling the parents and with a plan for follow up including routine eye, neurological examinations and a plan for dental referral in future. Chromosomal and genetic testing was not done due to financial constraints.

\section{DISCUSSION:}

IP is an ectodermal dysplasia where skin and its appendages, endovasculature and central nervous system (CNS) are affected. IP is typically identified by its unique skin manifestations that appear in four stages and is the first notable clinical manifestation. Vesiculobullous lesions are noted on torso and extremities from birth to 2 weeks which proceed to verrucous hyperkeratotic papules. Classical whorls and streaks of brown pigmentation following lines of Blaschko are seen from late infancy to puberty. The fourth stage is manifested by adolescence which comprises of pale, hairless, atrophic patches and/or hypopigmentation. Vertex alopecia is the commonest hair manifestation of $\mathrm{IP}^{3}$. Prevalence of nail dystrophy in IP is uncertain and may regress with time. Dental anomalies which include partial/ total adonentia, pegged and conical teeth are the mostly seen non-cutaneous manifestation ${ }^{3}$. CNS manifestations include infantile spasms, seizure disorder, spastic paralysis, learning disabilities and microcephaly.

IP is an X-linked dominant genetic disorder caused by a mutation in the IKBKG (NEMO) gene which codes for proteins preventing cellular apoptosis ${ }^{4}$. Affected hemizygous male foetuses demise in utero, but males with milder forms of gene mutation, mosaicism and XXY karyotype may survive ${ }^{2}$. The diagnosis of IP is mainly based on clinical evaluation. Molecular genetic testing is also available. Skin biopsy may be helpful in females with questionable findings in resource poor settings. Diagnostic criteria are being brought up by Mini $\mathrm{S}$ et al which includes any stage of skin manifestations of IP as the major criterion. The minor criteria consist of non-cutaneous anomalies and multiple male miscarriages ${ }^{5}$. Histopathological findings of IP are also considered as a minor criterion ${ }^{5}$. Presence of IKBKG mutation and presence of a relative with IP are also considered in making a diagnosis 5 . Ophthalmological evaluation by a paediatric ophthalmologist is a must. Repeated eye evaluations and fluorescein angiograms are needed since the eye manifestations are severe but be effectively treated with early identification. A thorough examination of skin and its appendages and a detailed neurological examination is 
warranted on follow up. MRI brain with or without angiography and electroencephalography are indicated if seizures, neurological abnormalities or retinal changes are present. A detailed evaluation of the mother is important since in some, manifestations can be very mild and missed.

Treatment is purely supportive ${ }^{6}$. Skin manifestations may disappear with growth. In newborn a local antiseptic can be used for vesiculobullous lesions to prevent secondary infections. Topical corticosteroids may be used to control the inflammation when it is severe. To prevent skin inflammation and pigmentation photoprotective measurements are recommended. Laser treatment should be avoided on hyperpigmented lesions since it results in recurrent cutaneous inflammation. Retinal neovascularization is treated with cryotherapy and laser photocoagulation to prevent retinal detachment. Appropriate rehabilitation is needed when developmental delay and/or intellectual disabilities are present. Since dental anomalies may interfere with feeding and speech, timely interventions are important. Genetic counselling is a key aspect in management.

\section{REFERENCES:}

01. Fusco F, Paciozlla M, Conte MI, Pescatore A, Esposito E, Mirabelli P, et al. Incontinentia pigmenti: report on data from 2000 to 2013. Orphanet J Rare Dis. 2014;9:93

02. National Organization for Rare Disorders [home page on the internet].Danbury. Available from https://rarediseases.org/rare diseases/incontinentia-pigmenti/

03. Landy SJ, Donnai D. Incontinentia pigmenti (Bloch-Sulzberger syndrome). J Med Genet 1993;30:53-9.
04. Berlin AL, Paller AS, Chan LS. Incontinentia pigmenti: a review and update on the molecular basis of pathophysiology. J Am Acad Dermatol.2002;47(2):169-190. doi:10.1067/mjd.2002.125949

05. Mini S, Trpinac D, Obradovi M. Incontinentia pigmenti diagnostic criteria update. Clin Genet. 2014;85(6):536-542. doi:10.1111/ cge. 12223

06. National Foundation For Ectodermal Dysplasia-Incontinentia pigmenti [home page on the internet]. https://www.nfed.org/learn/ types/incontinentia-pigmenti/

\footnotetext{
${ }^{1}$ Senior Registrar in Paediatrics- Professorial Paediatric Unit, Colombo South Teaching Hospital

\author{
${ }^{2}$ Senior Lecturer in Paediatrics- Faculty \\ of Medical Sciences, University of Sri \\ Jayewardenepura
}

${ }^{3}$ Registrar in Paediatrics- Professorial Paediatric Unit, Colombo South Teaching Hospital

Corresponding author:
NEkneligoda
nnekneligoda@yahoo.com 